\title{
Hepatitis delta genotype 5 is associated with favourable disease outcome and better response to treatment compared to genotype 1
}

\section{Graphical abstract}

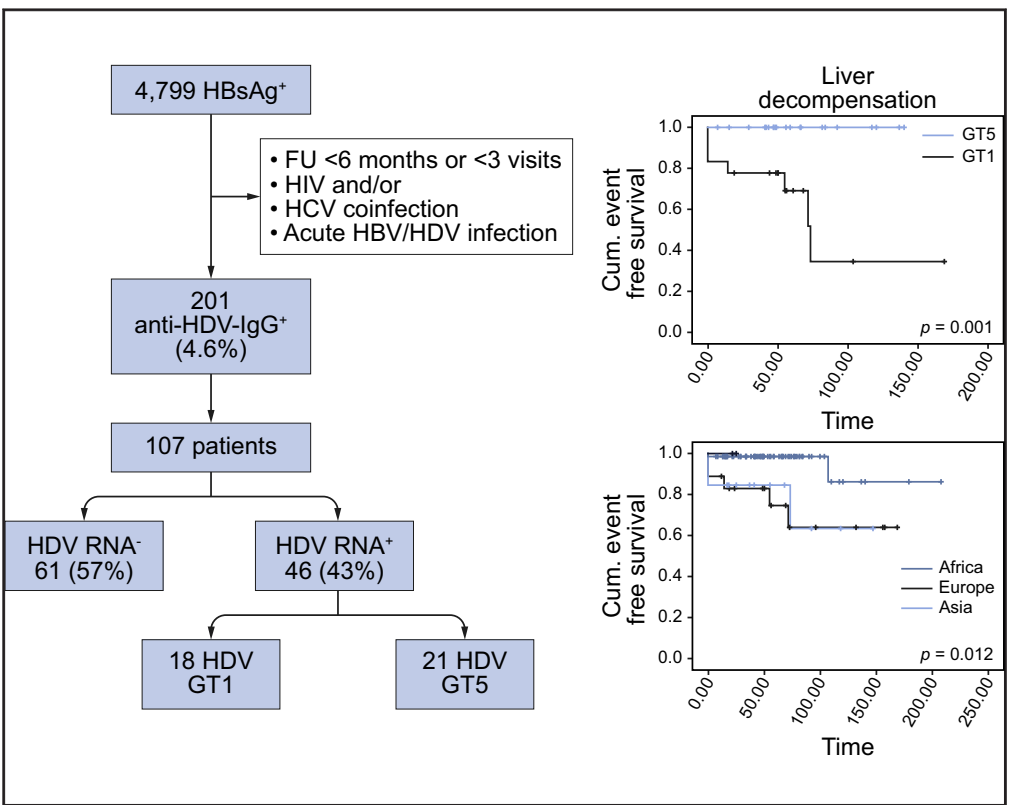

Highlights

- Patients of African origin who contract HDV less often have cirrhosis.

- Patients with HDV and detectable viral load have worse clinical outcomes.

- Patients with HDV genotype 5 less often develop hepatic decompensation.

- Patients with HDV genotype 5 seem to respond better to peg-IFN treatment.

\section{Authors}

Michelle Spaan, Ivana Carey, Matthew Bruce, ..., Mary Horner, Geoff Dusheiko,

Kosh Agarwal

\section{Correspondence}

m.spaan@erasmusmc.nl (M. Spaan).

Lay summary

Hepatitis delta is a virus that affects the liver. The virus is known to have different subtypes, called genotypes. With this research we discovered that hepatitis delta virus genotype 1 behaves differently than genotype 5 and causes faster development of liver disease. This is important for education of our patients and to determine how often we need to check our patients. 


\title{
Hepatitis delta genotype 5 is associated with favourable disease outcome and better response to treatment compared to genotype 1
}

\author{
Michelle Spaan ${ }^{1,2, *}$, Ivana Carey ${ }^{1}$, Matthew Bruce ${ }^{1}$, Dazhuang Shang ${ }^{1}$, Mary Horner ${ }^{1}$, \\ Geoff Dusheiko ${ }^{1}$, Kosh Agarwal ${ }^{1}$ \\ ${ }^{1}$ Institute of Liver Studies, King's College Hospital, London, United Kingdom; ${ }^{2}$ Department of Gastroenterology and Hepatology, Erasmus MC, \\ Rotterdam, the Netherlands
}

\begin{abstract}
Background \& Aims: Coinfection with HDV causes rapid progression to liver cirrhosis and hepatic decompensation in patients with chronic hepatitis B. Factors that are associated with disease progression are poorly understood. In this study we aim to identify risk factors associated with disease progression and better characterise clinical differences and treatment response between HDV genotype 1 and 5 .
\end{abstract}

Methods: In this retrospective study, all patients under our care between 2005 and 2016 with HBV/HDV coinfection (HBsAg+, anti-HDV antibodies positive) were analysed. Patients were excluded if follow-up was less than 6 months, if they had HCV and/or HIV coinfection or an acute HDV infection. Demographic data, stage of liver disease, development of liver complications and treatment response were recorded.

Results: One-hundred seven patients (mean age 36.0 years, 57\% male) were followed for a median period of 4.4 years (range 0.6-28.1 years); $64 \%$ were of African origin and $17 \%$ were of European origin, with $28 \%$ of patients being cirrhotic at first visit; $43 \%$ patients had actively replicating HDV virus (anti-HDV-IgG+, anti-HDV-IgM+ or HDV RNA+) and 57\% of patients were HDV exposed (anti-HDV-IgG+, HDV RNA-). Patients with actively replicating HDV more often developed liver complications than HDV-exposed patients ( $p=0.002$ ), but no differences in baseline characteristics were observed. Patients with HDV genotype 5 less often developed cirrhosis or hepatic decompensation compared to patients with HDV genotype 1 . Twenty-four patients were treated with peg-IFN and post-treatment response was significantly better in patients infected with genotype 5 (10\% GT1 vs. $64 \%$ GT5, $p=0.013)$.

Conclusion: Patients infected with HDV genotype 5 appear to have a better prognosis with fewer episodes of hepatic decompensation and better response to peg-IFN treatment than patients infected with HDV genotype 1 .

Lay summary: Hepatitis delta is a virus that affects the liver. The virus is known to have different subtypes, called genotypes. With this research we discovered that hepatitis delta virus genotype 1 behaves differently than genotype 5 and causes faster

Keywords: Hepatitis B virus; HBsAg; Anti-HDV-IgG; HDV RNA; Liver decompensation.

Received 5 March 2019; received in revised form 29 December 2019; accepted 31 December 2019; available online $x x x$

* Corresponding author. Address: Erasmus MC, 's Gravendijkwal 230, 3015 CE Rotterdam, The Netherlands; Tel.: +31-641414312.

E-mail address: m.spaan@erasmusmc.nl (M. Spaan).

https://doi.org/10.1016/j.jhep.2019.12.028 development of liver disease. This is important for education of our patients and to determine how often we need to check our patients.

(c) 2020 Published by Elsevier B.V. on behalf of European Association for the Study of the Liver.

\section{Introduction}

Hepatitis delta virus (or HDV) is a single stranded RNA virus that infects around 15-20 million people worldwide. ${ }^{1}$ It is underdiagnosed and is the severest form of viral hepatitis with no effective treatment currently available. The virus is dependent on HBsAg for packaging and propagation of its virions, although HDV replication independent of HBV has been shown in liver transplant patients. ${ }^{2}$ HDV often leads to the accelerated progression to advanced hepatic fibrosis, increased risk of hepatocellular carcinoma and rapid decompensation. ${ }^{3,4}$ The prevalence varies greatly between regions, with rates from $0 \%$ to $40 \%$ in HBsAg-positive patients. HDV is known to be endemic in Mediterranean countries, the Middle East, parts of Brazil, Mongolia and central Africa. ${ }^{1,5}$ Due to the implementation of HBV vaccination programs, the incidence of HDV has significantly decreased in Europe. However, due to increased migration of people from highly endemic areas, this decline has recently reversed. ${ }^{6-8}$ It is well known that patients with actively replicating delta i.e. those with detectable HDV RNA, have more severe liver disease than those who are anti-HDV-IgG alone. To diagnose an actively replicating HDV infection in places where HDV RNA testing is not available, anti-HDV-IgM can be used. ${ }^{9,10}$ Little is known about the factors influencing spontaneous clearance of HDV RNA. Besides host factors, virus genotypic variability might be involved. Eight different genotypes were identified with $20-40 \%$ sequence divergence. Genotype 1 is the most prevalent and found worldwide. And while genotype 1 is the most prevalent in Africa, genotypes 5-8 are found exclusively in African patients and those who migrated to Europe. ${ }^{11-13} \mathrm{~A}$ small number of studies have reported differences in clinical outcome between hepatitis delta genotypes. ${ }^{14-17}$ The only available treatment option for HDV is pegylated interferon-alfa (peg-IFN), with only $15 \%-35 \%$ of patients achieving a sustained virologic response (SVR). ${ }^{18-21}$ Baseline factors that predict clinical outcomes are poorly defined.

In this study we aim to better characterise disease progression and treatment response in a mixed cohort of patients of predominantly European and African origin, as well as to identify factors that predict disease progression and treatment response. 


\section{Patients and methods \\ Patient population}

Between January 2005 and December 2016, all 4,977 HBsAgpositive patients attending the outpatient clinic in King's College Hospital, London were routinely screened for anti-HDV-IgG. Twohundred and one patients (4.6\%) were found to be positive and were further analysed for our study (Fig. 1). The following groups were excluded: $14 \mathrm{HIV}$ coinfected patients, 4 patients with HCV coinfection (HCV RNA+) and 76 patients with follow-up for less than 6 months or less than 3 consecutive visits. In addition, 4 patients with HDV superinfection at diagnosis were excluded from the study. From 107 patients, clinical characteristics and liverrelated endpoints were recorded. Cirrhosis was defined by liver biopsy (ISHAK score $\geq F 5$ ), transient elastography ( $>12.5 \mathrm{kPa}$ on Fibroscan) or if patients had signs of cirrhosis via radiological criteria. This observational single centre study was conducted following the ethical principles of the Declaration of Helsinki and had ethical approval.

\section{Virological testing}

Serological markers of HBV, HCV and HIV were tested by commercial Chemiluminescent microparticle immunoassays (CMIAs) on Abbott ARCHITECT i2000 SR (Abbott Laboratories, North Chicago, IL). Anti-HDV-IgG, anti-HDV-IgM were tested using ETIDELTA-IGMK-2 and ETI-AB-DELTAK-2 (Diasorin S.p.A 13040 Saluggia (vc), Italy). HDV RNA and HDV genotype were tested using an in-house quantitative HDV RNA assay with a lower limit of quantification of $640 \mathrm{IU} / \mathrm{ml},{ }^{22}$ direct sequencing using $A B I 3130 \times 1$ genetic analyser (Life Technologies, Carslbad, CA) and phylogenetic tree analysis using neighbour-joining ( $\mathrm{NJ}$ ) distance analyses software (njplot, v 2.0). HBV DNA was tested using the Roche Cobas AmpliPrep/Cobas TaqMan assay with a lower limit of quantification of $20 \mathrm{IU} / \mathrm{ml}$. HBV genotypes were determined by in-house nucleic acid amplification and direct sequencing using an ABI 3130×l genetic analyser (Life Technologies, Carslbad, CA). Since HDV RNA levels are known to fluctuate over time, patients were classified as having actively replicating HDV infection if HDV RNA was detected once during follow-up and/or anti-HDVIgM was positive. For missing data, stored samples were retested using the assays above. Patients were classified as HDV exposed if HDV RNA was undetectable during follow-up for at least 3 repeated measured and anti-HDV-IgM was negative.

\section{Statistical analyses}

For normally distributed variables, unpaired $t$ test was used for unpaired data. Paired continuous variables that were not normally distributed were assessed by Wilcoxon's rank-sum test and unpaired variables by the Mann-Whitney $U$ test. Categorical data were compared using Fisher's exact test. Survival was calculated using Kaplan-Meier's method and compared using log-rank test. Spearman rank correlation test was used to calculate a correlation between 2 non-parametric values. Hazard ratios (HRs) were calculated using Cox proportional Hazard model. Statistical significance was considered at a $p<0.05$ level. All analyses were performed using SAS software (v9.4; SAS institute, Inc., Cary, NC.)

\section{Results}

\section{Baseline demographics}

A total of 107 patients were included in our study (mean age 36.0 years [range 16.5-61.7 years]). Patients' clinical and demographic

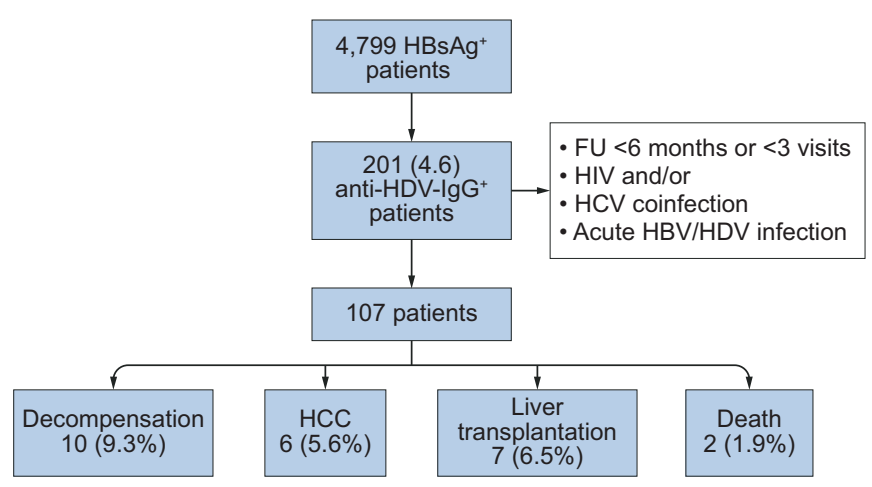

Fig. 1. Demographic characteristics and exclusion criteria of the patients at entry and development of liver-related endpoints along follow-up.

characteristics are shown in Table 1. Interestingly, in contrast to other studies from Europe ${ }^{23-25}$ that mainly reported on patients born in Eastern Europe and Central Asia, our cohort consists of a large population born in (West or sub-Saharan) Africa (64.5\%). There were 2 different patterns of HBV and HDV genotype distribution in our cohort. There was a strong correlation between HDV and HBV genotype $(p<0.001)$ and origin $(p<0.001)$; patients with HBV genotype D were mostly infected with HDV genotype 1 $(10 / 10,100 \%)$ in contrast to patients with HBV genotype $\mathrm{E}$ who were all infected with HDV genotype 5 (13/13, 100\%). Forty-three (40.4\%) patients had detectable HDV RNA levels during their follow-up and 33 (30.6\%) patients had positive anti-HDV-IgM. All patients with detectable HDV RNA and/or anti-HDV-IgM were classified as having actively replicating HDV infection. As expected, patients who were only HDV exposed (undetectable HDV RNA and negative anti-HDV-IgM) had significantly less cirrhosis $(p<0.001)$, and appeared to have less advanced liver disease with lower aspartate aminotransferase $(p<0.001)$, alanine aminotransferase (ALT; $p<0.001)$, bilirubin ( $p=0.037$ ), international normalized ratio $(p=0.008)$ and higher albumin $(p=0.042)$ compared to patients with actively replicating HDV (Table 1 ). In addition, 78\% of HDV-exposed patients had normal ALT ( $<45$ IU/ $\mathrm{ml}$ ) upon presentation. The baseline event-anticipation (BEA) score, designed to calculate the risk of developing a liver-related complication in 5 years, was calculated for all groups (Table 1). The presence of cirrhosis at first visit was significantly different between patients of African ( $n=12,17.4 \%)$, Asian $(n=5,38.5 \%)$ and European origin ( $\mathrm{n}=9,50 \%, p=0.023)$. However, no differences were observed for age, time of follow-up, gender or HBV genotype between HDV-exposed patients and patients who had actively replicating HDV (Table 1). On the first visit, 11 patients (10\%) were on nucleos(t)ide analog (NUC) treatment: 3 patients on tenofovir, 5 on entecavir, 1 on a combination of lamivudine and adefovir and 2 on peg-IFN/tenofovir. On the last visit 42 patients (39\%) were on NUC treatment.

\section{Disease progression}

All patients with anti-HDV-IgG were followed for a median period of 4.4 years (range 0.6-28.1 years). Among the 77 patients that did not have cirrhosis at baseline, 2 patients progressed to cirrhosis. At baseline, 2 patients were already decompensated and 8 patients experienced at least 1 episode of liver decompensation during follow-up (Table S1). Liver decompensation throughout this study is defined as Child-Pugh >B7 or the 
Table 1. Baseline characteristics between HDV-exposed patients and those with actively replicating HDV.

\begin{tabular}{|c|c|c|c|c|}
\hline & All patients & $\begin{array}{r}\text { Exposed HDV } \\
\text { undetectable HDV RNA } \\
\end{array}$ & $\begin{array}{r}\text { Actively replicating HDV } \\
\text { detectable HDV RNA and/or anti-HDV-IgM }\end{array}$ & $p$ value $^{*}$ \\
\hline Number & 107 & 61 & 46 & \\
\hline Age years, mean \pm SD (range) & $36.0 \pm 10.4(16.5-61.7)$ & $36.6 \pm 4.7(17.3-61.7)$ & $35.1 \pm 10.4(16.5-59.8)$ & 0.493 \\
\hline Gender, male & $57(53.3)$ & $30(49.2)$ & $27(58.7)$ & 0.218 \\
\hline Follow-up, years & $4.4(0.6-28.1)$ & $2.0(0.7-28.1)$ & $4.1(0.6-14.1)$ & 0.485 \\
\hline Origin & $\begin{array}{r}18 \text { Europe } \\
13 \text { Asia } \\
69 \text { Africa } \\
2 \text { N. America }\end{array}$ & $\begin{array}{r}8 \text { Europe } \\
7 \text { Asia } \\
43 \text { Africa } \\
1 \text { N. America }\end{array}$ & $\begin{array}{r}10 \text { Europe } \\
6 \text { Asia } \\
26 \text { Africa } \\
1 \text { N. America }\end{array}$ & 0.567 \\
\hline HBV genotype & $\begin{array}{r}7 \text { A } 2 \text { C } \\
22 \text { D } 53 \text { E }\end{array}$ & $\begin{array}{r}4 \mathrm{~A} \quad 1 \mathrm{C} \\
12 \mathrm{D} \quad 36 \mathrm{E}\end{array}$ & $\begin{array}{r}3 \mathrm{~A} \quad 1 \mathrm{C} \\
10 \mathrm{D} \quad 17 \mathrm{E}\end{array}$ & 0.688 \\
\hline HBeAg positive & $10(9.4)$ & $6(9.8)$ & $4(8.9)$ & 0.573 \\
\hline HBsAg level IU/ml & $6.4 \times 10^{3}\left(0.03-1.1 \times 10^{5}\right)$ & $6.8 \times 10^{3}\left(0.03-2.7 \times 10^{4}\right)$ & $6.4 \times 10^{3}\left(544-1.1 \times 10^{5}\right)$ & 0.695 \\
\hline HBV DNA IU/ml & $50.1\left(0-1.8 \times 10^{8}\right)$ & $91.1\left(0-1.7 \times 10^{8}\right)$ & $32\left(0-1.8 \times 10^{8}\right)$ & 0.138 \\
\hline HDV genotype & $\begin{array}{l}18 \text { GT1 } \\
21 \text { GT5 }\end{array}$ & 61 unknown & $\begin{array}{l}18 \text { GT1 } \\
21 \text { GT5 }\end{array}$ & \\
\hline HDV RNA IU/ml & $0\left(0-8.7 \times 10^{8}\right)$ & $0(0-0)$ & $4.2 \mathrm{E} 4\left(0-8.7 \times 10^{6}\right)$ & $<0.001$ \\
\hline Detectable HDV RNA & $43(40.2)$ & 0 & $43(93.4)$ & $<0.001$ \\
\hline Detectable anti-HDV-IgM & $33(31.4)$ & 0 & $33(73.3)$ & $<0.001$ \\
\hline Cirrhosis & $30(28)$ & 7 (11.5) & $23(50)$ & $<0.001$ \\
\hline ALT IU/L & $40.0(2-573)$ & $25.0(2-185)$ & $66.0(14-573)$ & $<0.001$ \\
\hline AST IU/L & $36.0(13-372)$ & $29.0(13-342)$ & $58.0(24-372)$ & $<0.001$ \\
\hline Platelets $\times 109 / \mathrm{L}$ & $192.0(28-372)$ & $197.0(95-372)$ & $171.5(28-332)$ & 0.045 \\
\hline Bilirubin $\mu \mathrm{mol} / \mathrm{L}$ & $10.0(3-257)$ & $9.0(3-24)$ & $11.0(3-257)$ & 0.037 \\
\hline Albumin $\mathrm{mmol} / \mathrm{L}$ & $44.0(21-83)$ & $44.0(27-49)$ & $43.0(21-83)$ & 0.042 \\
\hline INR & $1.1(0.9-2.7)$ & $1.0(0.9-1.4)$ & $1.1(0.9-2.7)$ & 0.008 \\
\hline BEA scores A-B-C & $\begin{array}{r}71 \mathrm{~A} \\
31 \mathrm{~B} \\
3 \mathrm{C}\end{array}$ & $\begin{array}{r}45 \mathrm{~A} \\
14 \mathrm{~B} \\
2 \mathrm{C}\end{array}$ & $\begin{array}{r}26 \mathrm{~A} \\
17 \mathrm{~B} \\
1 \mathrm{C}\end{array}$ & 0.057 \\
\hline
\end{tabular}

Data presented as median (range), or $\mathrm{n}(\%)$ unless stated otherwise.

ALT, alanine aminotransferase; AST, aspartate aminotransferase; BEA, baseline event-anticipation; GT, genotype; INR, international normalised ratio.

${ }^{*}$ Comparison made between patient groups with exposed and actively replicating HDV infection. For normally distributed variables (age), unpaired $t$ test was used. For data that were not normally distributed, Mann-Whitney $U$ test was used. Categorical data were compared using Fisher's exact test.
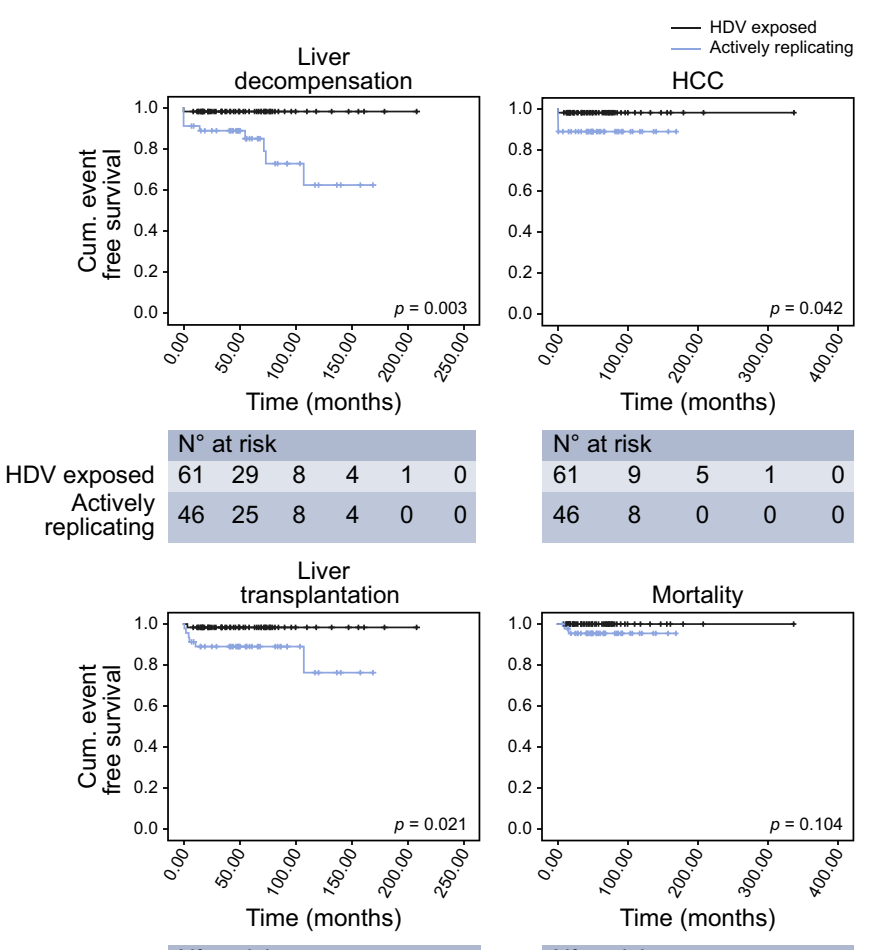

\begin{tabular}{r|cccccc} 
HDV exposed & 61 & 29 & 8 & 4 & 1 & 0 \\
$\begin{array}{r}\text { Actively } \\
\text { replicating }\end{array}$ & 46 & 24 & 8 & 2 & 0 & 0
\end{tabular}

\begin{tabular}{|ccccc}
\hline$N^{\circ}$ & at risk & & & \\
61 & 8 & 1 & 1 & 0 \\
46 & 8 & 0 & 0 & 0
\end{tabular}

Fig. 2. Cumulative event-free survival in patients who are HDV exposed or have actively replicating HDV. Survival was calculated using Kaplan-Meier's method and compared using log-rank test. HCC, hepatocellular carcinoma. presence of ascites or a variceal bleed. Nine patients developed ascites and 4 patients had a variceal bleed. Six patients developed hepatocellular carcinoma (HCC), all diagnosed within 3 months of the first visit. Seven patients required a liver transplant and 2 patients died of a liver-related event (Fig. 1, Table S1). Time to development of a liver-related event was strongly associated with the presence of cirrhosis $(p<0.001)$, but not with HBeAg status $(p=0.443)$, HBV genotype $(p=0.157)$, having detectable HBV DNA ( $p=0.459$, all Kaplan Meier survival analysis) or age $(\mathrm{r}=-0.17 ; p=0.079$, Spearman correlation test $)$.

Comparison between patients with actively replicating HDV or exposure to $H D V$

Patients with actively replicating HDV developed significantly more episodes of decompensation $(p=0.002)$, ascites $(p=0.005)$ variceal bleeding $(p=0.032)$ and more often received a liver transplant ( $p=0.043$ ) compared to HDV-exposed patients during follow-up (Table S1). Survival analysis showed that HDV-exposed patients had better liver event-free survival compared to patients with actively replicating HDV (Fig. 2). Because of the low event score, HRs were only calculated for composite clinical events (decompensation, HCC, liver transplantation and mortality). The HR for exposed vs. active HDV was 7.29 (95\% CI 2.43-21.87; $p=$ 0.0024 ). In line with the lower presence of cirrhosis, patients of African origin less frequently developed decompensation compared to patients of European or Asian origin in survival analyses (Fig. S1). No differences in baseline factors such as platelet count, alkaline phosphatase levels, fibroscan results, fibrosis-4 (FIB-4) or albumin-bilirubin (ALBI) scores were observed between African vs. non-African patients (results not shown). 
Table 2. Patient characteristics of patients with HDV genotype 1 and 5.

\begin{tabular}{|c|c|c|c|}
\hline & HDV genotype 1 & HDV genotype 5 & $p$ value \\
\hline Number & 18 & 21 & \\
\hline Age, years & $36.9(16.5-59.8)$ & $33.3(17.4-43.6)$ & 0.215 \\
\hline Gender, male & $11(61.1)$ & $13(61.9)$ & 1.000 \\
\hline Follow-up, years & $4.7(1.2-14.1)$ & $4.7(0.6-11.7)$ & 0.955 \\
\hline Origin & $\begin{array}{l}9 \text { Europe } 5 \text { Asia } \\
2 \text { Africa } 2 \text { unknown }\end{array}$ & $\begin{array}{r}0 \text { Europe } 0 \text { Asia } \\
21 \text { Africa }\end{array}$ & $<0.001$ \\
\hline HBV genotype & $\begin{array}{r}1 \mathrm{~A} 10 \mathrm{D} \\
0 \mathrm{E} 7 \text { unknown }\end{array}$ & $\begin{array}{r}1 \mathrm{~A} \quad 0 \mathrm{D} \\
13 \mathrm{E} 7 \mathrm{unknown}\end{array}$ & $<0.001$ \\
\hline HBeAg positive & $1(5.6)$ & $3(14.3)$ & $0.60 s$ \\
\hline HBsAg level IU/ml & $3.9 \times 10^{3}\left(544-2.9 \times 10^{4}\right)$ & $7.0 \times 10^{3}\left(1.1 \times 10^{3}-1.1 \times 10^{5}\right)$ & 0.432 \\
\hline HBV DNA IU/ml & $10.25\left(0-4.4 \times 10^{6}\right)$ & $36.5\left(0-1.8 \times 10^{8}\right)$ & 0.184 \\
\hline HDV RNA IU/ml & $6.9 \times 10^{4}\left(0-8.3 \times 10^{5}\right)$ & $2.7 \times 10^{5}\left(944-8.7 \times 10^{6}\right)$ & 0.477 \\
\hline Detectable HDV RNA, \% & 100 & 100 & 1.000 \\
\hline Detectable anti-HDV-IgM & $17(94.4)$ & $13(61.9)$ & 0.023 \\
\hline Cirrhosis & $12(66.7)$ & $6(28.6)$ & 0.026 \\
\hline ALT IU/L & $66.0(39-126)$ & $90.5(32-573)$ & 0.338 \\
\hline AST IU/L & $61.0(34-175)$ & $55(28-513)$ & 0.693 \\
\hline Platelets * $109 / \mathrm{L}$ & $163.0(48-332)$ & $201.0(28-321)$ & 0.115 \\
\hline Bilirubin $\mu \mathrm{mol} / \mathrm{L}$ & $12.0(5-63)$ & $11.0(3-33)$ & 0.224 \\
\hline Albumin $\mathrm{mmol} / \mathrm{L}$ & $42.5(21-50)$ & $43.0(25-83)$ & 0.524 \\
\hline INR & $1.1(0.9-1.6)$ & $1.1(0.9-1.4)$ & $0.48 \mathrm{~s}$ \\
\hline FIB-4 scores & $1.11(0.3-7.4)$ & $1.29(0.4-6.8)$ & 0.942 \\
\hline ALBI score & $-2.97(-3.3-0.6)$ & $-2.97(-6.4-1.8)$ & 0.464 \\
\hline \multirow[t]{3}{*}{ BEA scores A-B-C } & $8 \mathrm{~A}$ & $15 \mathrm{~A}$ & \multirow[t]{3}{*}{0.299} \\
\hline & $8 \mathrm{~B}$ & $6 \mathrm{~B}$ & \\
\hline & $1 \mathrm{C}$ & $0 \mathrm{C}$ & \\
\hline
\end{tabular}

Data presented as median (range), or $\mathrm{n}(\%)$ unless stated otherwise.

ALBI, albumin-bilirubin; ALT, alanine aminotransferase; AST, aspartate aminotransferase; BEA, baseline event-anticipation; FIB-4, fibrosis-4; INR, international normalised ratio.

*For normally distributed variables (age), unpaired T test was used. For data that were not normally distributed, Mann-Whitney $U$ test was used. Categorical data were compared using Fisher's exact test.

HDV genotype 5 is associated with favourable disease progression compared to HDV genotype 1

Of 43 patients with actively replicating HDV, 39 patients had samples available for genotyping; 21 patients were found to have genotype 1 and 18 patients were infected with genotype 5 (Table 2). As expected, most patients with genotype 5 were of African origin (100\%) and had HBV genotype E (93\%) whereas patients with genotype 1 were predominantly of European origin (56\%) and were infected with HBV genotype D (91\%). Age, gender and median follow-up time were similar for both groups. Levels of HBV DNA were low and comparable in both groups and no differences were observed in levels of HDV RNA and HBsAg. The ALBI and the FIB-4 score were calculated and showed no differences. Interestingly, although patients of both genotypes had comparable liver function tests, the presence of liver cirrhosis at the time of diagnosis was more prevalent in patients with genotype 1 infection ( $p=0.026$, Table 2 ). At first visit, patients with HDV genotype 1 tended to have higher BEA-scores, but this did not reach statistical significance. During follow-up, patients with HDV genotype 1 were more likely to develop an episode of hepatic decompensation $(p=0.001)$, and to receive a liver transplant $(p=0.025$, Fig. 3, Table S2). HR was calculated for composite clinical events (decompensation, HCC, liver transplantation and mortality). HR for genotype 5 vs. genotype 1 was 5.40 (95\% CI $1.65-17.70)$ with a $p$ value of 0.015 . Focussing only on patients with cirrhosis, none of the 6 patients with genotype 5 developed hepatic decompensation during follow-up, while 7 out of $12(58 \%)$ patients with genotype 1 developed liver decompensation $(p=0.038)$.
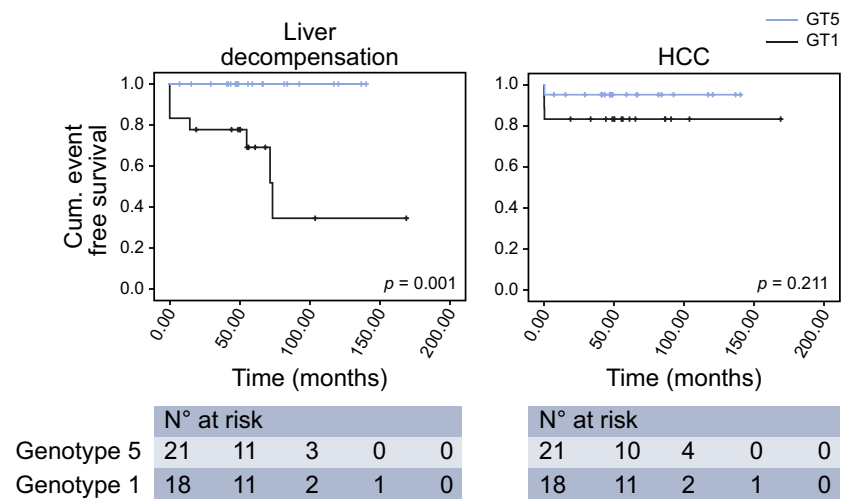

Genotype $1 \quad 18 \quad 11 \quad 2 \quad 1 \quad 10$

Liver
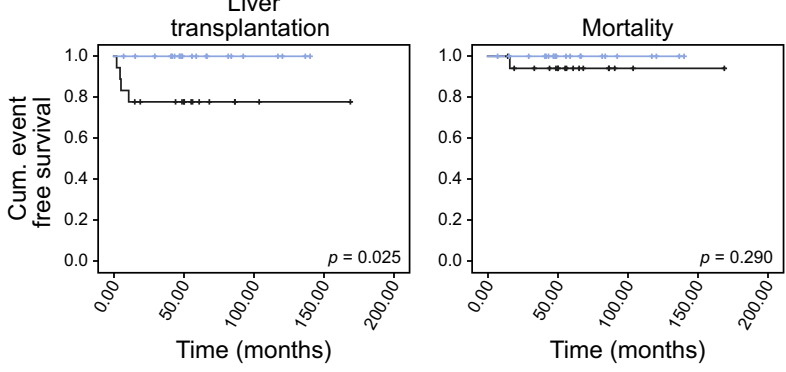

$\begin{array}{llllll}\text { Genotype } 5 & 21 & 11 & 3 & 0 & 0\end{array}$

\begin{tabular}{|lrlll}
\multicolumn{2}{|l}{$N^{\circ}$ at risk } & & & \\
21 & 11 & 3 & 0 & 0 \\
18 & 12 & 2 & 1 & 0
\end{tabular}

Fig. 3. Cumulative event free survival in patients who have HDV genotype 1 or HDV genotype 5. Survival was calculated using Kaplan-Meier's method and compared using log-rank test. 
Table 3. Patients characteristics of patients that underwent peg-interferon treatment.

\begin{tabular}{|c|c|c|c|c|}
\hline & All patients & Non-response & Response & $p$ value ${ }^{*}$ \\
\hline Number & 25 & 14 & 11 & 0.695 \\
\hline Age years & $33.9(17.8-52.3)$ & $30.0(17.8-50.1)$ & $34.5(22.1-52.3)$ & 0.200 \\
\hline Gender, male & $12(48)$ & $6(43)$ & $6(55)$ & 0.695 \\
\hline Cirrhosis & $12(48)$ & $8(57)$ & $4(36)$ & 0.428 \\
\hline \multirow[t]{2}{*}{ HBV genotype } & $2 \mathrm{~A} 5 \mathrm{D}$ & $0 \mathrm{~A} 5 \mathrm{D}$ & $2 \mathrm{~A} \quad 0 \mathrm{D}$ & 0.032 \\
\hline & $11 \mathrm{E}$ & $4 \mathrm{E}$ & $7 \mathrm{E}$ & \\
\hline \multirow[t]{2}{*}{ HDV genotype } & 10 GT 1 & 9 GT 1 & 1 GT 1 & 0.013 \\
\hline & 14 GT 5 & 5 GT 5 & 9 GT 5 & \\
\hline HIV & $3(12)$ & $2(14)$ & $1(9)$ & 1 \\
\hline \multirow[t]{2}{*}{ Origin } & 7 Europe & 6 Europe & 1 Europe & 0.078 \\
\hline & 17 Africa & 7 Africa & 10 Africa & \\
\hline IFN-treatment weeks & $48.0(9-80)$ & $48.0(18-80)$ & $48.0(9-53)$ & 0.267 \\
\hline Follow-up after treatment months & $51.2(6.4-116.5)$ & $49.8(25.8-116.5)$ & $51.3(6.4-112.4)$ & 0.936 \\
\hline HDV RNA IU/ml & $3.5 \times 10^{5}\left(0-1.1 \times 10^{8}\right)$ & $5.9 \times 10^{5}\left(2.9 \times 10^{4}-1.1 \times 10^{8}\right)$ & $1.8 \times 10^{4}\left(0-2.1 \times 10^{6}\right)$ & 0.002 \\
\hline HBV DNA level IU/ml & $41.8\left(0-1.9 \times 10^{6}\right)$ & $53.8\left(0-1.8 \times 10^{5}\right)$ & $0\left(0-1.9 \times 10^{6}\right)$ & 0.893 \\
\hline HBsAg level IU/ml & $8.3 \times 10^{3}\left(1.6 \times 10^{3}-4.6 \times 10^{4}\right)$ & $8.7 \times 10^{3}\left(2.6 \times 10^{3}-4.6 \times 10^{4}\right)$ & $6.8 \times 10^{3}\left(1.6 \times 10^{3}-2.0 \times 10^{4}\right)$ & 0.422 \\
\hline Detectable anti-HDV-IgM & $16(64)$ & $10(71)$ & $6(54.5)$ & 0.673 \\
\hline
\end{tabular}

Data presented as median (range), or $\mathrm{n}(\%)$ unless stated otherwise.

GT, genotype; peg-IFN, pegylated interferon.

${ }^{*}$ Comparison made between patient groups with response and non-response to Peg-IFN therapy. For normally distributed variables (age), unpaired $t$ test was used. For data that were not normally distributed, Mann-Whitney $U$ test was used. Categorical data were compared using Fisher's exact test.

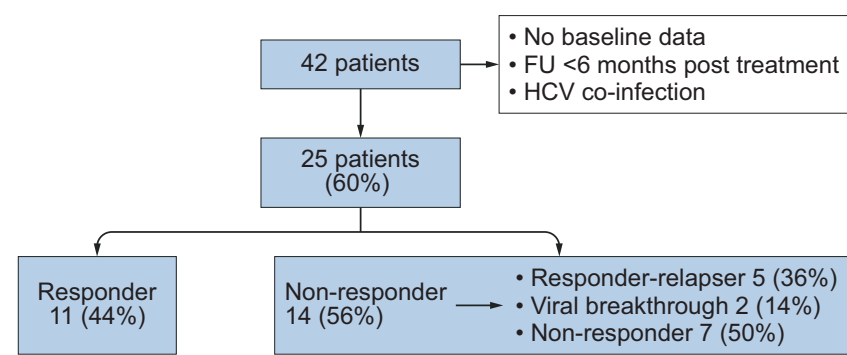

Fig. 4. Demographic characteristics and exclusion criteria of the patients who were treated with peg-IFN and their response to treatment. peg-IFN, pegylated interferon.

\section{Antiviral therapy}

From our cohort of 201 patients with positive anti-HDV-IgG, 42 patients were treated with peg-IFN. Patients were excluded for this analysis if baseline data were not available $(n=15)$, if followup was less than 6 months post treatment $(n=1)$ or if patients were coinfected with HCV $(\mathrm{n}=1)$. Twenty-five patients were included with a median age of 33.9 years (range 17.8-52.3 years). Patient characteristics at the start of antiviral therapy are shown in Table 3. None of the patients received peg-IFN therapy in the past. Median HDV RNA at the start of therapy was $10^{5}$, comparable to levels at first visit. There was 1 patient with an exceptionally high HDV RNA level of $10^{8}$ who eventually had a nonresponse. Ten (40\%) patients were infected with HDV genotype 1 vs. 14 (56\%) with genotype 5 . We were not able to determine genotype in 1 patient. From 25 treated patients, 16 patients were HDV RNA negative at the end of therapy: 11 patients maintained HDV RNA status more than 6 months after completing therapy but 14 patients had a non-response; 5 patients relapsed - 4 within 6 months after stopping therapy and 1 patient relapsed after 22 months; 2 had a viral breakthrough on therapy and 7 patients were total non-responders (Fig. 4). HBsAg levels decreased during peg-IFN treatment but this was not statistically significant (Table 3) and no seroconversions were observed.

Baseline characteristics of both responders and nonresponders did not differ by age, gender or presence of

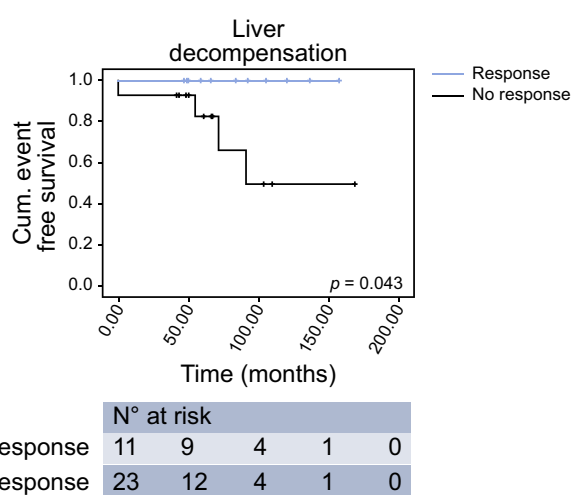

Fig. 5. Cumulative event free survival of any episode of liver decompensation in patients with or without a response to peg-IFN treatment. Survival was calculated using Kaplan-Meier's method and compared using log-rank test. peg-IFN, pegylated interferon.

cirrhosis. Differences were found for HBV genotype ( $p=0.032)$ and baseline HDV RNA level ( $p=0.002$, Table 3 ). Patients from Africa tended to respond better to peg-IFN, but this did not reach statistical significance $(p=0.078)$. Duration of peg-IFN treatment was significantly shorter in patients with genotype 5 compared to genotype 1 (median duration was 48 weeks for both genotypes, but mean duration was 38 weeks $v s$. 54 weeks, $p=0.007$ ). Treatment was discontinued for various reasons including pregnancy, poor adherence and side-effects. Strikingly, although treatment duration was shorter in patients with HDV genotype 5 , 6-month response rates after stopping therapy were higher in comparison to patients with genotype 1 infection (64\% genotype 5 vs. $10 \%$ genotype $1, p=0.013$, Table 3 ). Survival analysis showed that treatment response was associated with improved clinical outcome at follow-up ( $p=0.043$, Fig. 5).

\section{Discussion}

This study evaluated the clinical outcomes of a diverse patient population with positive anti-HDV-IgG antibodies in the United Kingdom. The proportion of HBsAg-positive patients with positive anti-HDV total antibodies was $4.3 \%$. Surprisingly, only $43 \%$ of 
anti-HDV total positive patients had detectable HDV RNA. The presence of HDV RNA in serum is required to diagnose actively replicating HDV infection and is an important factor determining rapid development of cirrhosis and poor clinical outcome. ${ }^{16,24}$ One explanation might be a relatively low sensitivity of the assay used and the possibility that low levels of HDV RNA were not detected. However, all patients with undetectable HDV RNA were tested on several occasions repeatedly and were also antiHDV IgM negative. Patients in our cohort with undetectable HDV RNA and anti-HDV-IgM had stable disease and normal or mildly elevated liver enzymes, indicating they do not have actively replicating delta infection. Interestingly, none of the patients with undetectable HDV RNA had received peg-IFN previously and it is therefore likely that these patients spontaneously cleared their HDV virus after acute coinfection or superinfection. The proportion of patients with spontaneous HDV clearance may even be underestimated since patients who may have cleared HBsAg are not included in this cohort. To get more insight into mechanisms involved in clearance of HDV, we compared baseline characteristics of patients with actively replicating and exposed HDV, but no differences were observed. It is suspected that other factors might contribute to spontaneous viral clearance, namely mode of transmission, age at time of contraction and mode of infection (super vs. coinfection) and it would be of interest to focus future studies on these aspects. One explanation for the low proportion of patients with HDV RNA viremia is the relative high number of patients of African origin. Epidemiological studies from Africa have demonstrated that $35-62 \%$ of patients have detectable HDV RNA in serum, ${ }^{5,26-28}$ which appears lower than studies from Europe and Asia that have shown that $70-93 \%$ of patients with anti-HDV-IgG have detectable HDV RNA levels. ${ }^{16,25,29,30}$

The ability to clear hepatitis delta is likely to be influenced by host and viral factors. A small number of studies have reported differences in clinical outcome between hepatitis delta genotypes. Independent of HBV genotype, infection with genotype 1 delta seems to be more damaging than genotype $2 \cdot{ }^{15,16}$ Genotype 3 has been associated with acute liver damage in an area of the Amazon $^{14}$ and genotype 4 seems to behave differently in various regions. $^{15,17}$ To our knowledge, this is the first study to fully characterise patients infected with HDV genotype 5 and compare its disease progression with patients infected with genotype 1 . In this study we provide evidence that African patients have a milder course of disease compared to non-African HDV patients on 3 levels. i) African patients less often present with cirrhosis at first visit compared to non-African patients; ii) African patients less often developed the clinical hard endpoints such as decompensation compared to non-African patients and iii) Resolved HDV occurred more frequently in African patients.

One of the mechanisms that could clarify different outcomes between patients and HDV genotypes is variability in viral replication and virion assembly efficacy leading to a lower rate of HDV virion secretion and therefore slower infection of hepatocytes. $^{16,31,32}$ Host factors like race and single-nucleotide polymorphisms causing differences in entry receptors might also play a role.

Our cross-sectional, single-centre study has limitations as it focuses only on a small number of patients and is retrospective. However, this is a hepatitis virus that is poorly understood with little data on genotypic heterogeneity. It appears that patients of African origin are more likely to be exposed to HDV than have actively replicating HDV. To better understand whether this difference is due to the variation in HDV genotype, interactions between specific HBV and HDV genotypes or to the absence of HDV RNA in circulation in the exposed patients, more prospective, multicentre studies are needed. In addition, we were not able to separate the effect of HBV-related damage from HDV as high concordance between HDV and HBV genotypes was demonstrated.

In our patients with actively replicating HDV infection, 23 patients (50\%) were cirrhotic at first presentation to our centre. Of the cirrhotic patients, 9 patients (39\%) decompensated during a mean follow-up of 4.8 years, with an incidence rate of 8.0 per 100 person-years. The overall incidence rate of decompensation episodes was lower than in other studies. ${ }^{24,25,29}$ Between these studies, patient characteristics varied greatly but it is possible that the low incidence of decompensation in our cohort reflects the high number of patients with genotype 5 who had a lower rate of decompensation than patients with HDV genotype 1.

Peg-IFN treatment has poor tolerability and factors predicting the outcome of peg-IFN are not well understood. Some studies have shown that neither cirrhosis nor liver biochemical tests at baseline affect the response to treatment, ${ }^{18,33,34}$ while others appear to suggest that patients with cirrhosis or advanced disease respond less well. ${ }^{21,35}$ Several studies have reported that after 6 months of therapy, a negative HDV-RNA was predictive of sustained response. ${ }^{18,36}$ However, late-relapse often occurs and negative HDV-RNA 6 months post-treatment does not seem to predict response or prevent relapse. ${ }^{34}$ In our cohort, 25 patients were treated with peg-IFN therapy for a median period of 48 weeks. Eleven patients (44\%) had a treatment response, which is similar to the result of a recent large European trial. ${ }^{20}$ Treatment response has been defined as undetectable HDV RNA at least 6 months post-treatment; however this does not seem to be a reliable end-point and late relapse occurs frequently; ${ }^{34}$ only loss of $\mathrm{HBsAg}$ could be classed as sustained virological response in delta patients. Indeed, although most patients relapsed within 6 months post-treatment, 1 patient had a relapse 22 months posttreatment. Treatment responses are likely to be accurate in our cohort as there is long-term follow up. Of note, the patient with a relapse 22 months post-treatment had positive anti-HDV-IgM during and after treatment, which might suggest an ongoing antibody response to small amounts of virus that are still present in concentrations below the detection limit of our HDV RNA quantitative assay. In future studies anti-HDV-IgM might help to define treatment response, although in a previous study, antiHDV IgM did not show a correlation with level of HDV replication but did show a correlation with disease activity. ${ }^{10}$ We show that treatment response to peg-IFN is associated with lower disease progression, which is in line with results from Wranke et $\mathrm{al}^{30}$ Importantly, patients with genotype 5 appeared to respond better to peg-IFN treatment than patients with HDV genotype 1 , while treatment duration was slightly shorter. This was not statistically shown in patients of African origin, most likely due to the presence of both genotype 1 and 5 in this patient population. Because of small numbers and retrospective design, prospective randomized clinical trials including patients with HDV genotype 5 are required to confirm this clinical observation.

In summary, this study demonstrates that disease progression and clinical outcomes are associated with HDV genotypic heterogeneity. We demonstrate that patients with HDV genotype 5, 


\section{JOURNAL

predominantly of African origin, have a favourable disease outcome compared to patients with genotype 1 and appear to have a better treatment response to peg-IFN. Identifying the risk factors for decompensation is important for patient education, clinical management and to delineate patients who need meticulous follow-up.

\section{Abbreviations}

ALBI, albumin-bilirubin; ALT, alanine aminotransferase; AST, aspartate aminotransferase; BEA, baseline event-anticipation; FIB-4, fibrosis-4; HCC, hepatocellular carcinoma; HRs, hazard ratios; INR, international normalised ratio; NJ, neighbourjoining; NUCs, nucleos(t)ide analogs; peg-IFN, pegylated interferon.

\section{Financial support}

Dr. Agarwal reports grants and personal fees from Gilead, personal fees from Arbutus, personal fees from Springbank, grants from MSD, personal fees from Vir, personal fees from Shinoigi, outside the submitted work. Dr. Dusheiko reports grants from Gilead Sciences, personal fees from Gilead Sciences, during the conduct of the study; Personal fees donated 2018-2019 donated to UNICEF and Mozambique cyclone relief fund.

\section{Conflicts of interest}

The authors declare no conflicts of interest that pertain to this work.

Please refer to the accompanying ICMJE disclosure forms for further details.

\section{Authors' contributions}

Michelle Spaan: study concept and design, acquisition of data, analysis and interpretation of data, drafting of the manuscript, statistical analysis. Ivana Carey: study concept and design, analysis and interpretation of data, critical revision of the manuscript. Matthew Bruce: acquisition of data, technical support. Dazhuang Shang: acquisition of data, technical support. Mary Horner: acquisition of data, technical support. Geoff Dusheiko: critical revision of the manuscript. Kosh Agarwal: study supervision, critical revision of the manuscript.

\section{Supplementary data}

Supplementary data to this article can be found online at https:// doi.org/10.1016/j.jhep.2019.12.028.

\section{References}

Author names in bold designate shared co-first authorship

[1] Hughes SA, Wedemeyer H, Harrison PM. Hepatitis delta virus. Lancet 2011;378:73-85.

[2] Lempp FA, Ni Y, Urban S. Hepatitis delta virus: insights into a peculiar pathogen and novel treatment options. Nat Rev Gastroenterol Hepatol 2016;13:580-589.

[3] Fattovich G, Giustina G, Christensen E, Pantalena M, Zagni I, Realdi G, et al. Influence of hepatitis delta virus infection on morbidity and mortality in compensated cirrhosis type B. The European Concerted Action on Viral Hepatitis (Eurohep). Gut 2000;46:420-426.

[4] Rizzetto M. The adventure of delta. Liver Int 2016;36(Suppl 1):135-140.

[5] Andernach IE, Leiss LV, Tarnagda ZS, Tahita MC, Otegbayo JA, Forbi JC, et al. Characterization of hepatitis delta virus in sub-Saharan Africa. J Clin Microbiol 2014;52:1629-1636.
[6] Wedemeyer H, Heidrich B, Manns MP. Hepatitis D virus infection-not a vanishing disease in Europe! Hepatology 2007;45:1331-1332. author reply $1332-1333$.

[7] Cross TJ, Rizzi P, Horner M, Jolly A, Hussain MJ, Smith HM, et al. The increasing prevalence of hepatitis delta virus (HDV) infection in South London. J Med Virol 2008;80:277-282.

[8] William Tong CY, Asher R, Toby M, Ngui SL, Tettmar K, Ijaz S, et al. A reassessment of the epidemiology and patient characteristics of hepatitis D virus infection in inner city London. J Infect 2013;66:521-527.

[9] Wedemeyer H, Manns MP. Epidemiology, pathogenesis and management of hepatitis D: update and challenges ahead. Nat Rev Gastroenterol Hepatol 2010;7:31-40.

[10] Wranke A, Heidrich B, Ernst S, Calle Serrano B, Caruntu FA, Curescu MG, et al. Anti-HDV IgM as a marker of disease activity in hepatitis delta. PLoS One 2014;9:e101002.

[11] Radjef N, Gordien E, Ivaniushina V, Gault E, Anais P, Drugan T, et al. Molecular phylogenetic analyses indicate a wide and ancient radiation of African hepatitis delta virus, suggesting a deltavirus genus of at least seven major clades. J Virol 2004;78:2537-2544.

[12] Le Gal F, Gault E, Ripault MP, Serpaggi J, Trinchet JC, Gordien E, et al. Eighth major clade for hepatitis delta virus. Emerg Infect Dis 2006;12:1447-1450.

[13] Makuwa M, Caron M, Souquiere S, Malonga-Mouelet G, Mahe A, Kazanji M. Prevalence and genetic diversity of hepatitis B and delta viruses in pregnant women in Gabon: molecular evidence that hepatitis delta virus clade 8 originates from and is endemic in central Africa. J Clin Microbiol 2008;46:754-756.

[14] Casey JL, Brown TL, Colan EJ, Wignall FS, Gerin JL. A genotype of hepatitis D virus that occurs in northern South America. Proc Natl Acad Sci U S A 1993;90:9016-9020.

[15] Wu TT, Bichko VV, Ryu WS, Lemon SM, Taylor JM. Hepatitis delta virus mutant: effect on RNA editing. J Virol 1995;69:7226-7231.

[16] Su CW, Huang YH, Huo TI, Shih HH, Sheen IJ, Chen SW, et al. Genotypes and viremia of hepatitis B and D viruses are associated with outcomes of chronic hepatitis D patients. Gastroenterology 2006;130: $1625-1635$.

[17] Watanabe H, Nagayama K, Enomoto N, Chinzei R, Yamashiro T, Izumi N, et al. Chronic hepatitis delta virus infection with genotype IIb variant is correlated with progressive liver disease. J Gen Virol 2003;84:3275-3289.

[18] Castelnau C, Le Gal F, Ripault MP, Gordien E, Martinot-Peignoux M, Boyer $\mathrm{N}$, et al. Efficacy of peginterferon alpha-2b in chronic hepatitis delta: relevance of quantitative RT-PCR for follow-up. Hepatology 2006;44:728-735.

[19] Erhardt A, Gerlich W, Starke C, Wend U, Donner A, Sagir A, et al. Treatment of chronic hepatitis delta with pegylated interferon-alpha2b. Liver Int 2006;26:805-810.

[20] Wedemeyer H, Yurdaydin C, Dalekos GN, Erhardt A, Cakaloglu Y, Degertekin $\mathrm{H}$, et al. Peginterferon plus adefovir versus either drug alone for hepatitis delta. N Engl J Med 2011;364:322-331.

[21] Yurdaydin C, Keskin O, Kalkan C, Karakaya F, Caliskan A, Kabacam G, et al. Interferon treatment duration in patients with chronic delta hepatitis and its effect on the natural course of the disease. J Infect Dis 2018;217:11841192.

[22] Shang D, Hughes SA, Horner M, Bruce MJ, Dong Y, Carey I, et al. Development and validation of an efficient in-house real-time reverse transcription polymerase chain reaction assay for the quantitative detection of serum hepatitis delta virus RNA in a diverse South London population. J Virol Methods 2012;184:55-62.

[23] Heidrich B, Deterding K, Tillmann HL, Raupach R, Manns MP, Wedemeyer H. Virological and clinical characteristics of delta hepatitis in Central Europe. J Viral Hepat 2009;16:883-894.

[24] Romeo R, Del Ninno E, Rumi M, Russo A, Sangiovanni A, de Franchis R, et al. A 28-year study of the course of hepatitis Delta infection: a risk factor for cirrhosis and hepatocellular carcinoma. Gastroenterology 2009;136:1629-1638.

[25] Buti M, Homs M, Rodriguez-Frias F, Funalleras G, Jardi R, Sauleda S, et al. Clinical outcome of acute and chronic hepatitis delta over time: a longterm follow-up study. J Viral Hepat 2011;18:434-442.

[26] Foupouapouognigni Y, Noah DN, Sartre MT, Njouom R. High prevalence and predominance of hepatitis delta virus genotype 1 infection in Cameroon. J Clin Microbiol 2011;49:1162-1164.

[27] Mansour W, Bollahi MA, Hamed CT, Brichler S, Le Gal F, Ducancelle A, et al. Virological and epidemiological features of hepatitis delta 
infection among blood donors in Nouakchott, Mauritania. J Clin Virol 2012;55:12-16.

[28] Honge BL, Jespersen S, Medina C, Te Dda S, da Silva ZJ, Lewin S, et al. Hepatitis B and Delta virus are prevalent but often subclinical coinfections among HIV infected patients in Guinea-Bissau, West Africa: a crosssectional study. PLoS One 2014;9:e99971.

[29] Niro GA, Smedile A, Ippolito AM, Ciancio A, Fontana R, Olivero A, et al. Outcome of chronic delta hepatitis in Italy: a long-term cohort study. J Hepatol 2010;53:834-840.

[30] Wranke A, Serrano BC, Heidrich B, Kirschner J, Bremer B, Lehmann P, et al, Antiviral treatment and liver-related complications in hepatitis delta. Hepatology 2017;65:414-425.

[31] Lin FM, Lee CM, Wang TC, Chao M. Initiation of RNA replication of cloned Taiwan-3 isolate of hepatitis delta virus genotype II in cultured cells. Biochem Biophys Res Commun 2003;306:966-972.
[32] Hsu C, Tsou HH, Lin SJ, Wang MC, Yao M, Hwang WL, et al. Chemotherapyinduced hepatitis B reactivation in lymphoma patients with resolved HBV infection: a prospective study. Hepatology 2014;59:2092-2100.

[33] Niro GA, Ciancio A, Gaeta GB, Smedile A, Marrone A, Olivero A, et al. Pegylated interferon alpha-2b as monotherapy or in combination with ribavirin in chronic hepatitis delta. Hepatology 2006;44:713-720.

[34] Heidrich B, Yurdaydin C, Kabacam G, Ratsch BA, Zachou K, Bremer B, et al. Late HDV RNA relapse after peginterferon alpha-based therapy of chronic hepatitis delta. Hepatology 2014;60:87-97.

[35] Gunsar F, Akarca US, Ersoz G, Kobak AC, Karasu Z, Yuce G, et al. Two-year interferon therapy with or without ribavirin in chronic delta hepatitis. Antivir Ther 2005;10:721-726.

[36] Yurdaydin C, Bozkaya H, Onder FO, Senturk H, Karaaslan H, Akdogan M, et al. Treatment of chronic delta hepatitis with lamivudine vs lamivudine + interferon vs interferon. J Viral Hepat 2008;15:314-321. 